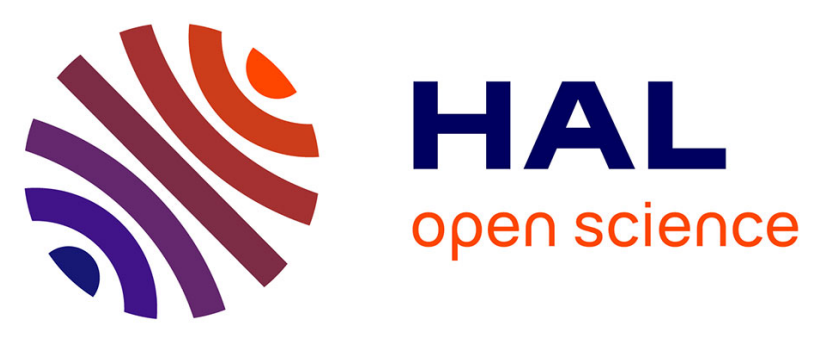

\title{
Bags-of-Features for fish school cluster characterization in pelagic ecosystems: application to the discrimination of juvenile and adult anchovy clusters off Peru
}

Ronan Fablet, Paul Gay, Salvatore Peraltilla, Cecilia Peña, Ramiro Castillo, Arnaud Bertrand

\section{To cite this version:}

Ronan Fablet, Paul Gay, Salvatore Peraltilla, Cecilia Peña, Ramiro Castillo, et al.. Bags-of-Features for fish school cluster characterization in pelagic ecosystems: application to the discrimination of juvenile and adult anchovy clusters off Peru. Canadian Journal of Fisheries and Aquatic Sciences, 2012, 69 (8), pp.1329 - 1339. 10.1139/f2012-064 . hal-00945357

\section{HAL Id: hal-00945357 \\ https://hal.science/hal-00945357}

Submitted on 20 Feb 2014

HAL is a multi-disciplinary open access archive for the deposit and dissemination of scientific research documents, whether they are published or not. The documents may come from teaching and research institutions in France or abroad, or from public or private research centers.
L'archive ouverte pluridisciplinaire HAL, est destinée au dépôt et à la diffusion de documents scientifiques de niveau recherche, publiés ou non, émanant des établissements d'enseignement et de recherche français ou étrangers, des laboratoires publics ou privés. 
Bags-of-Features for fish school cluster characterization in pelagic ecosystems: application to the discrimination of juvenile and adult anchovy clusters off Peru. Castillo $^{3}$, Arnaud Bertrand ${ }^{2,3,5}$.

2. Institut de Recherche pour le Développement (IRD), UMR 212 IFREMER/IRD/UM2, Av. Jean Monnet, BP 171, 34203 Sète Cedex, France

3. IMARPE, Esquina Gamarra y General Valle S/N Chucuito, Callao, Lima, Peru

4. Université européenne de Bretagne

5. Universidad Nacional Mayor de San Marcos, Lima, Peru 


\begin{abstract}
Whereas fisheries acoustics data processing mainly focused on the detection, characterization and recognition of individual fish schools, here we addressed the 35 characterization and discrimination of fish school clusters. The proposed scheme relied on the application of the Bags-of-Features $(\mathrm{BoF})$ approach to acoustic echograms. This approach is widely exploited for pattern recognition issues and naturally applies here, considering fish schools as the relevant elementary objects. It relies on the extraction and categorization of fish schools in fisheries acoustic data. Echogram descriptors were

40 computed per unit echogram length as the numbers of schools, in different school categories. We applied this approach to the discrimination of juvenile and adult anchovy (Engraulis ringens) off Peru. Whereas the discrimination of individual schools is low (below 70\%), the proposed BoF scheme achieved between $89 \%$ and $92 \%$ of correct classification of juvenile and adult echograms for different survey datasets and significantly

45 outperformed classical school-based echogram characteristics (about 10\% of improvement of the correct classification rate). We further illustrate the potential of the proposed scheme for the estimation of the spatial distribution of juvenile and adult anchovy populations.
\end{abstract}

Keywords: fisheries acoustics, pelagic ecosystems, fish schools, school categorization, 50 bags-of-features. 


\section{Introduction}

Fisheries acoustics provide a unique remote sensing device to monitor pelagic ecosystems, especially pelagic resources (Simmonds and MacLennan 2005). While the

55 analysis of acoustic echograms serves as a basis for the operational assessment of a number of pelagic stocks, fisheries acoustics data can characterize the spatial distribution of marine resources. Such a characterization is of key interest for the development of the ecosystem approach to fisheries (Koslow 2009). Among others, one may cite the discrimination of physical structures (e.g. oxycline depth (Bertrand et al. 2010)), biological communities

60 (e.g., zooplankton and pelagic fish; ( Kloser et al. 2009, Lebourges-Dhaussy et al. 2009, Ballon et al. 2011,), the description of schooling behaviour (Axelsen et al. 2001, Gerlotto et al. 2004, Bertrand et al. 2006) as well as descriptors of the patchiness of pelagic fish distribution (Barange 1994, Bertrand et al. 2004, Gutierrez et al. 2007).

For gregarious fish, the school is "an essential life unit in which fish feed, breed,

65 rest, and flee" (Aoki 1980, p.3). This schooling behavior of pelagic fish suggests that school-based procedures provide the most natural approaches to the analysis of fisheries acoustics data (Fréon and Misund 1999, Simmonds and MacLennan 2005). Early developments have focused on the detection, characterization and recognition of fish schools (Haralambous and Georgakarakos 1996, Scalabrin et al. 1996). More recently,

70 species-based school discrimination has seen renewed interest using multi-frequency characterization and advanced pattern recognition models (Jech and Michaels 2006, Anderson et al. 2007, Lefort et al. 2011). Though schools appear to be the key unit structures of the distribution of pelagic fish, other analysis scales are of interest, such as 
clusters of fish schools (Hammond et al. 2001, Petitgas et al. 2001, Burgos and Horne

75 2008). The characterization of fish school clusters relies on the definition of global features of the echograms (typically, echograms of a few nautical miles). In contrast to the schoollevel analysis mentioned above, this approach is referred to hereafter as an echogram-level analysis and will rely on the extraction of echogram-level characteristics. Very few works have addressed such an echogram-level analysis (Petitgas et al. 2001, Burgos and Horne

80 2008). Petitgas et al. (2001) investigated such an approach to match echograms to species mixtures, whereas Burgos and Horne (2008) showed that echogram-level features discriminated pollock school patterns.

In this work, we propose a novel approach to extract school-based echogram-level characteristics. Whereas such descriptors were derived as univariate statistics of each

85 school feature in previous works (Petitgas et al. 2001, Burgos and Horne 2008), we exploit a multivariate approach based on a prior categorization of fish schools, termed in the pattern recognition literature as "Bag-of-Features" (BoF) (Sivic and Zisserman 2003). This representation, derived from the "Bag-of-Words" which is used in text document analysis (Salton and McGill 1983), provides a meaningful while compact characterization of the

90 distribution of fish schools within an echogram through the count of schools assigned to each school category. This methodology is applied to the discrimination of juvenile and adult anchovy (Engraulis ringens) populations off Peru.

The Peruvian anchovy fishery is the world's largest (in weight) (Chavez et al. 2008). The follow-up of the state of the anchovy population mainly relies on seasonal 95 acoustic surveys. The management of this fishery involves fishing-free areas with a view to protecting the juvenile population. The definition of these fishing-free areas relies on 
scientific surveys, as well as at-sea observers and landings monitoring. In particular, areas in which juvenile anchovy make up more than $10 \%$ of the total catch may be closed to fishing. Here we show that the proposed echogram-level analysis could enable the

100 discrimination and mapping of the juvenile and adult anchovy populations from fisheries acoustics survey data. We analyze the relevance of the results with respect to inter-survey variabilities and expert interpretation and discuss potential prospects offered by the proposed approach.

\section{Material and methods}

105 Data

Biannual scientific surveys carried out by IMARPE (Peruvian Sea Institute) off Peru provided datasets comprising fisheries acoustics data along with trawl catch data (Gutierrez et al. 2007, Simmonds et al. 2009) Since 2008, bi-frequency acoustic echograms have been acquired with a $38 \mathrm{kHz}$ and $120 \mathrm{kHz}$ hull mounted Simrad EK60 echosounder along

110 transects of the Peruvian coast. Both frequencies were processed using Echoview software to achieve the extraction and the characterization of the fish schools observed in the echograms. Only schools observed at both frequencies were retained for our analysis. Based on a preliminary analysis of variance (significance level of 0.25 ) and correlation (correlation coefficients lower than 0.9) of energetic and geometric school features for the

115 considered survey datasets, we considered the following school descriptors: area $(A)$, compactness $(C$, i.e. the ratio between the perimeter and the squared-root surface), the elongation ( $E$, i.e. the ratio between the height and the width), shape rugosity $(R$, i.e. the ratio between the perimeter and the squared-root surface), mean acoustic energy density 
(acoustic volume backscattering strength, $\left.S_{V}\right)$, the coefficient of variation $(C V)$, skewness $120(S k)$ and kurtosis $(K)$ of acoustic energy values within the school, the school depth for the $38 \mathrm{kHz}$ frequency as well the difference between the surface and mean and total acoustic energies at both frequencies.

In addition to fisheries acoustics data, trawl catch data were also available (Fig. 1). These included the distribution in weight of fish species in the catches as well as the 125 associated length distributions. Each trawl catch was associated with an acoustic echogram (typically, the 6 nautical mile -nmi- echogram including the trawled area). In this study, we focused on the anchovy population and retained the echograms for which anchovy represented more than $50 \%$ of the total weight of the catches. It is known that sexual maturity typically occurs for the Peruvian anchovy at about one year old, between 10 and

$13012 \mathrm{~cm}$ in length (Zuzunaga 2002). We then discriminated between juvenile and adult anchovy echograms as follows: when the number of individuals below $11 \mathrm{~cm}$ represented more than $75 \%$ of the captured anchovy, the echogram was classified as juvenile anchovy. Conversely, when the individuals above $11 \mathrm{~cm}$ represented more than $75 \%$ of the captured anchovy, the echogram was classified as adult anchovy.

135 As a result, we were provided with a two-class dataset of echograms. This procedure was applied to three scientific surveys, namely, those carried out in the Austral summer 2010, spring 2010 and summer 2011. We summarized the data available for each survey (Table 1) and reported examples of acoustic echograms (Figure 2). 


\section{Echogram-level descriptors from school clustering}

Our study relied on the application of the Bags-of-Features (BoF) approach to acoustic echograms (Sivic and Zisserman 2003) and exploited a multivariate analysis of school characteristics within an echogram. By contrast, the analysis of school feature quantiles as in (Burgos and Horne 2008, Petitgas et al. 2001) processes each school feature independently and does not convey information on the relationships between school

145 features. Here, with the the BoF approach, we achieve a multivariate characterization of the distribution of the schools within an echogram.

We report an overview of the main processing steps of the BoF approach in Figure 3. It involves two main steps: the definition of fish school categories from an unsupervised analysis of fish school characteristics and the computation of the BoF vector for any

150 echogram from the categorization of the schools detected in the echogram. We detail these two steps subsequently.

Definition of fish school categories from unsupervised clustering: The proposed framework initially performed unsupervised feature-based clustering (categorization) of the school dataset using a Gaussian mixture model (GMM) (Bishop 2006). A GMM was

155 applied to the dataset formed by the feature vectors of all the schools detected in the considered echograms. Formally, it resorted to modeling the distribution of the schools in the considered feature space as:

$$
p\left(X_{s}\right)=\sum_{k=1}^{K} \pi_{k} g\left(X_{s} \mid M_{k}, \Sigma_{k}\right)
$$


where $X_{s}$ is the feature vector associated with any school $s, K$ the number of components of 160 the mixture model (i.e., the number of school categories), $\pi_{k}$ the prior probability of the $k^{\text {th }}$ component of the mixture model and $g(\cdot \mid M, \Sigma)$ a multivariate Gaussian distribution with mean $M$ and covariance $\Sigma . \mathrm{M}_{\mathrm{k}}$ and $\Sigma_{\mathrm{k}}$ refer to the mean and covariance of the $k^{\text {th }}$ component of the mixture model. Given a school dataset with associated feature vector dataset $\left\{X_{s}\right\}$, we used the EM (Expectation-Maximization) procedure to estimate the parameters $\pi_{k}, M_{k}$

165 and $\Sigma_{k}$ of each component of the mixture model according to the maximum likelihood criterion (Bishop 2006), Here, the GMM was parameterized with 20 components $(K=20)$ and diagonal covariance models were considered. An empirical sensitivity analysis in terms of classification performance demonstrated that this parameter setting is a good trade-off between computational complexity and robustness. The GMM was implemented using

170 Matlab and the Netlab toolbox (The Netlab toolbox can be downloaded from the webpage: http://www1.aston.ac.uk/eas/research/groups/ncrg/resources/netlab/).

Computation of echogram-level BoF vectors: Given the estimated GMM model, the BoF vector is defined as the number of times a given school category occurs in a processed echogram. This computation then relied on the assignment of any school to one of the

175 identified school categories. For a given school $s$, the assigned category $c_{s}$ was the most likely one given school characteristics $X_{s}$, i.e.:

$$
c_{S}=\arg \max _{k} p\left(C_{S}=k \mid X_{s}\right)
$$

The classification rule was evaluated from the estimated parameters of the mixture model as:

$$
c_{S}=\arg \max _{k} \pi_{k} g\left(X_{s} \mid M_{k}, \Sigma_{k}\right)
$$


At the level of an echogram $E$, we computed the vector $H_{E}$ of the numbers of schools assigned to each category. Here $H_{E}$ is a 20-dimensional vector. This vector is termed BoF in the pattern recognition literature (Sivic and Zisserman 2003). It has been shown to provide a relevant and powerful global characterization of documents (text, images, videos)

185 where the categories refer to words in documents or local signatures or objects in images and videos (Salton and McGill 1983, Sivic and Zisserman 2003). From a statistical point of view, BoF representation can be regarded as a multivariate characterization of the distribution of object sets, where the objects (here, the schools) are characterized by a multidimensional feature vector. In this work, the BoF vector $H_{E}$ was normalized by the

190 actual length of the echogram to resort to the numbers of schools per echogram unit length (here, nautical mile) in each school category, referred to hereafter as the densities of each school category in the processed echogram.

For comparison purpose, we also investigated school-based descriptors of the echograms issued from percentiles of each feature in the echograms similarly to (Burgos

195 and Horne 2008, Petitgas et al. 2001). We computed for each echogram the $10^{\text {th }}, 20^{\text {th }}, 30^{\text {th }}$, $40^{\text {th }}, 50^{\text {th }}, 60^{\text {th }}, 70^{\text {th }}, 80^{\text {th }}$ and $90^{\text {th }}$ percentiles of the marginal of each school feature. They are referred to hereafter as the echogram-level marginal statistics Note that here we focused on school-based features and did not consider features computed from the raw acoustic echogram as in (Burgos and Horne 2008).

\section{Discrimination of juvenile and adult anchovy clusters off Peru}

Given echogram datasets as described above, we addressed the discrimination of juvenile and adult anchovy clusters off Peru based on the proposed echogram-level characterization. We exploited statistical learning, namely Support Vector Machines 
(SVMs). SVMs are among the most powerful supervised classifiers (Schölkopf and 205 Alexander 2002) and were previously applied to fisheries acoustics data (Fablet et al. 2009). Additional experiments, not reported here, proved that similar performance could be reached using other classifiers (e.g., random forests (Breiman 2001, Fernandes 2009)).

SVMs aim at maximizing the discrimination margin between classes and perform a non-linear classification using a kernel-based approach (Schölkopf and Alexander 2002).

210 Here, we used a Gaussian kernel. SVMs were applied to the discrimination of juvenile and adult anchovy echograms from the echogram-level feature vectors described above. A 10fold cross-validation procedure was applied to determine SVM hyper-parameters and estimate the correct classification rates for the two classes (Schölkopf and Alexander 2002). SVM hyper-parameters included kernel parameters (here, the standard deviation of the

215 Gaussian kernel, the SVM regularity parameter) and a feature selection procedure. This procedure involved initially sorting the echogram features according to their one-way ANOVA F-test statistics and evaluating SVM models trained with the $n$ first features where $n$ was incremented from 1 to the total number of features. When using the BoF framework, this procedure aimed at selecting the $n$ best school categories for the discrimination task.

220 When using the echogram-level marginal statistics, the SVM kernel was a Gaussian function of the sum of the distance between the marginal statistics for the considered school features and the feature selection procedure resorted to the selection of the $n$ best school features (i.e., $n$ among the 10 school features considered here). We implemented the SVM using the libsvm package for Matlab (Chang and Lin 2011).

We applied SVM classification to the three survey datasets separately. To test for the applicability of a classification model trained from a given survey to subsequent 
surveys, we also evaluated the classification performances of SVM models trained on one dataset to discriminate echograms from another dataset.

\section{Application to the spatial mapping of juvenile and adult anchovy populations}

As an application of the proposed echogram classification model, we considered the spatial mapping of the areas depicting predominantly juvenile and adult anchovy from survey data. For a given survey, we proceeded as follows. We first determined the spatial distribution of the anchovy population, termed below as the anchovy zone, from experts' species-based interpretation of the acoustic schools and trawl catches. We then trained a

235 SVM classification model, as described above, for the set of acoustic echograms associated with trawl catch data. We considered 6 nmi-long acoustic echograms. Similarly the acoustic transect data was segmented in 6 nmi-long acoustic echograms. Each resulting echogram within the anchovy zone was then classified as juvenile anchovy or adult anchovy by the trained SVM model. The resulting scattered data was interpolated to produce a map of the

240 spatial distribution of juvenile and adult anchovy. For comparison purposes, we computed such a map using only trawl catch data.

\section{Results}

\section{Discrimination performances from different echogram-level characteristics}

We evaluated the performance of the proposed echogram-level characteristics and

245 classification models, termed as SVM-BoF, for the discrimination of juvenile and adult anchovy clusters off Peru (Table 1). Our quantitative analysis involved a SVM model based on echogram-level marginal statistics of each school feature, termed as SVM-marginals, as well as (to?) the classification rates of a school-level SVM model, termed as SVM-school, 
trained to discriminate juvenile and adult anchovy schools. For this school-level 250 classification model, all anchovy schools in an acoustic echogram termed as juvenile anchovy were assigned to a juvenile school class, whereas schools in acoustic echograms termed as adult anchovy were assigned to an adult school class.

Reported results (Table 2) indicated that the discrimination of juvenile and adult anchovy could not be correctly achieved at the scale of the fish schools and a correct 255 classification rate below $70 \%$ was reported. They also demonstrated the clear improvements of the proposed echogram-level characterization (SVM-BoF) over echogram-level features computed as school feature quantiles ( $90 \%$ vs. $80 \%$ of average correct classification rate over the three datasets). Overall correct classification rates between $89 \%$ and $94 \%$ were reported for the three datasets for the proposed SVM-BoF

260 framework, indicating that juvenile and adult anchovy clusters depicted significantly different school BoF statistics. The SVM-BoF reached slightly greater classification rate for the adult class (an average, for the three datasets, of $93 \%$ of correct classification rate for adult anchovy clusters compared to $87 \%$ for juvenile anchovy clusters).

We evaluated the sensitivity of the classification performance with respect to the 265 definition of the dataset of juvenile and adult echograms (i.e., the length of the echogram, the minimum percentage (in weight) of anchovy in the catches and the minimum percentage of individuals below or above $11 \mathrm{~cm}$ in the anchovy catches). Classification performance proved stable (i.e., below $2 \%$ of variations of the mean correct classification rate) for echogram lengths between 3 and 6 nmi. For echogram length greater than 6 nmi,

270 poorer discrimination was reported (e.g., a loss of $8 \%$ of correct classification for summer 2010 data). Regarding the minimum percentage of anchovy in the catches $(50 \%$ in the 
results reported in Table 2) and the minimum percentage of individuals below or above 11 $\mathrm{cm}$ in the anchovy catches $(75 \%$ in the results reported in Table 2$)$, setting parameters more restrictively than those used for the experiments reported in Table 2 could lead to improved

275 discrimination performance, at the expense, however, of a reduction of the number of echograms in the processed datasets, which might impact the applicability of the model.

\section{Bi-frequency vs. single-frequency school features}

We tested whether or not the bi-frequency characterization of fish schools led to improved discrimination performances compared to a single-frequency analysis. We compared the classification performance reported above using both $38 \mathrm{kHz}$ and $120 \mathrm{kHz}$ to those obtained when using only one of the two frequencies (Table 3). Overall, a bifrequency characterization led to a more robust discrimination with a mean gain of $2 \%$ in correct recognition. It might be noted that a single-frequency $(120 \mathrm{kHz})$ characterization outperformed the bi-frequency analysis for the summer 2010 dataset. However, for other

285 datasets (resp. spring 2011 and summer 2011), the $38 \mathrm{kHz}$ and $120 \mathrm{kHz}$ school characteristics used alone resulted in a loss greater than $6 \%$ in correct classification. Overall, neither $38 \mathrm{kHz}$ nor $120 \mathrm{kHz}$ school features appeared significantly more discriminative and the bi-frequency characterization appeared as a relevant trade-off.

\section{Inter-survey applicability}

The Northern Humboldt Current system is known for its high temporal variability, depicting, for instance, important temporal variabilities in the spatial distribution of the biological components (e.g., patchiness of forage fish) (Gutierrez et al. 2007, Bertrand et al. 2008a). In this respect we evaluated to which extent a model obtained from a given survey 
dataset could be relevant to processing data from subsequent surveys. Results were

295 evaluated in terms of mean correct classification rate (Table 4). In all cases, we observed a decrease in the discrimination performance of juvenile and adult anchovy clusters compared to the results reported above (Table 2). For instance, whereas an overall discrimination rate of $91 \%$ was reported for the spring 2011 dataset, only $70 \%$ of correct classification was obtained when considering a model trained from the summer 2010 300 dataset. Similar observations were drawn from other combinations.

\section{Estimation of the spatial distribution of juvenile and adult anchovy}

As an application of the proposed echogram-level classification, we addressed the mapping of the distribution of the juvenile and adult anchovy populations. The estimated spatial distribution for the summer 2010 dataset was compared to a mapping issued from

305 the sole analysis of trawl catch data without any consideration of the available acoustic data (Fig. 4). Overall, both mappings shared similar global characteristics. This stressed the consistence of the obtained echogram classification model compared to the sole use of catch data, which can be regarded as a coarse reference. The proposed approach also resulted in a finer mapping of the distribution of juvenile and adult anchovy, whereas the

310 necessarily sparse sampling associated with catch data might fail to identify some adult or juvenile clusters (e.g., the southern coastal area).

\section{Discussion}

\section{Echogram-level analysis and characterization of fisheries acoustics data}

The analysis of fisheries acoustics data generally relies on the extraction and 315 characterization of individual fish schools or on the echo-integration of the acoustic energy 
within a predefined layer (Simmonds and MacLennan 2005). As proven here, such analysis may not provide the relevant scale for the characterization of clusters of schools.

In this respect, we developed an echogram-level analysis, where an echogram typically corresponds to a few nautical miles along the survey transects. We aimed at 320 characterizing the distribution and organization of the schools within an area. Following (Burgos and Horne 2008, Petitgas et al. 2001), we stressed for Peruvian anchovy that a spatial scale of a few nautical miles reveals key information on the spatial organization of pelagic fish. We showed that variations in the densities of different types of school categories could be a discriminative marker of this spatial organization (here, in relation to 325 maturity level), whereas individual schools could only be poorly discriminated. This echogram-level scale does not involve a single fish school but rather corresponds to groups or clusters of fish schools, generally comprising different types of schools. As such, the proposed approach could provide the basis for further exploring the spatial organization of pelagic fish beyond the scale of a single school, for instance the relationships between this 330 spatial organization and environmental factors, especially physical forcing (e.g., Barange 1994, Bertrand et al. 2008b). This issue was typically addressed based on patchiness descriptors and mean school features. The proposed school cluster analysis might relevantly complement these studies with the analysis of the joint spatial distribution of different school types and of the characteristic scale of the clusters, especially for multispecific 335 pelagic communities (Petitgas et al., 2001, Gutierrez et al. 2007). It might be noted that the echogram-level analysis could operate at a coherent analysis scale with respect to satellite ocean sensing data (e.g., sea surface temperature, ocean colour,.etc..). As a peculiar example, it could enable determination of the extent to which physical forcing may lead to 
a shift in aggregation patterns (e.g, smaller and deeper vs. larger and shallower schools), or 340 only to smooth variations of mean school features. This is of key interest in coastal upwelling systems, especially the Humboldt Current System strongly affected by global ENSO climate forcing (Bertrand et al. 2008b).

From a methodological point of view, in contrast to the few previous works investigating this issue (Burgos and Horne 2008, Petitgas et al. 2001), we did not restrict

345 ourselves to univariate marginal statistics of school features but we also evaluated the densities of school categories. The latter were determined from an unsupervised categorization of fish schools. The interest of the resulting echogram-level characteristics was two-fold. Since school categories referred to different types of schools (e.g., deeper vs. shallower schools and/or larger vs. smaller schools), these characteristics first revealed the 350 school categories associated with each echogram. Though these school categories could not be specifically assigned to any of the two classes (juvenile vs. adult anchovy), echograms could be discriminated not only from the presence or absence of given school categories but also from differences in the school densities of each category. The resulting echogram-level descriptors were shown to significantly outperform echogram-level statistics (Burgos and

355 Horne 2008, Petitgas et al. 2001). Compared to features proposed by Burgos et al. (2008), such as the overall density in schools or the overall occupancy (i.e., rate of pixels within fish schools), we distinguished different school categories and the reported results suggested that school clusters here differed in the occurrences and co-occurrences of different school types.

The considered BoF statistics emerged relatively recently as a powerful objectbased representation of image contents (Sivic and Zisserman 2003). It appeared particularly 
suited to fisheries acoustics data as fish schools provided a natural object concept for the computation of BoF. Future work will further explore this methodology in two directions. On the one hand, BoF could be complemented by an actual characterization of the spatial 365 patterns formed by fish schools based on point process statistics and models (Nguyen et al. 2012). On the other hand, local signatures (Nguyen et al. 2012) widely used for image processing and computer vision might also provide relevant alternatives, especially when fish schools are poorly defined (e.g., for night data).

\section{Application to the discrimination of juvenile and adult anchovy clusters off Peru}

We applied the proposed school-based echogram-level characteristics to the discrimination of juvenile and adult anchovy clusters off Peru. Relevant discrimination performance (about $90 \%$ correct classification) was reported for the three processed survey datasets. We showed that a bi-frequency characterization of fish schools slightly improved classification performance (typically, a mean gain of $2 \%$ of correct classification). Besides,

375 poor recognition rates below $70 \%$ were obtained at the scale of individual schools.

Consequently, though discriminative features specific to juvenile or adult anchovy schools were not identified (i.e., they both involved large as well as small schools), adult and juvenile areas differed significantly in the relative school densities of the 20 different categories we identified. A unique and efficient discriminative model could not, however,

380 be obtained for all three datasets. We further investigated the differences between predominantly juvenile and adult areas, from the analysis of schools densities with respect to school characteristics (Table 5). Different patterns, which were consistent across datasets, were identified for each class of echogram. In predominantly juvenile areas, school densities were greater compared to the densities for predominantly adult areas, for 
385 small schools depicting distributions of the backscattered energies with large mean values and less acute peaks around the mean (Table 5, variables $S, S_{V}$ and $K, \mathrm{p}<0.01$ for all datasets). This was in agreement with experts' priors on the behaviour of juvenile and adult anchovy. By contrast, school depth and compactness as well as the difference in mean backscattered energy at $38 \mathrm{kHz}$ and $120 \mathrm{kHz}$ did not depict such general patterns common

390 to all datasets. Noticeably, juvenile anchovy clusters were not characterized by lower densities of more superficial schools. The identified general patterns were, however, only relative as the slopes of these trends depicted great variabilities. This might explain why a generic classification model valid for all surveys could not be identified.

The distribution of the Peruvian anchovy population depicts great temporal 395 variabilities induced by a strong bottom-up structuring of the North Humboldt current system, with the physical forcing itself being particularly variable (Bertrand et al. 2008b, 2011, Chavez et al. 2008,). The exhibited differences between juvenile and adult anchovy clusters might then be interpreted as differences in the responses of juvenile and adult fish to their variable environment. Meanwhile, the ongoing conditions of the system, such as the 400 presence or absence of strong Kelvin waves (Bertrand et al. 2008b) (and the strength of the upwelling (Gutierrez et al. 2007, Bertrand et al. 2008b, Swartzman et al. 2008) might strongly drive the characteristics of anchovy school clusters (Bertrand et al. 2008a) and explain the observed temporal variability. The proposed school cluster characteristics provide the methodological basis to further investigate these relationships and provide a 405 better understanding of the forcing variables of the spatial organization of school clusters of anchovy and other pelagic species in the Humboldt Current system. 
The discrimination of juvenile and adult anchovy school clusters is a critical issue for the management of the Peruvian anchovy fishery. During the fishing season, anchovy landings are monitored in real time, and fishing zones in which juvenile anchovy catches

410 represent more than $10 \%$ of the total catch (in weight) are declared fishing-free zones for a few days. A method allowing to determine, in real time, if juveniles dominate a given area should allow for a better distribution of the fishing effort and limit the discarding of juveniles. Here, we showed that the analysis of fisheries acoustics data could help in the monitoring of predominantly juvenile anchovy areas. We demonstrated the refinement

415 obtained compared to the sole analysis of catch data. Such a mapping could be of great interest for the definition and update of fishing-free zones to preserve the juvenile anchovy population. So far, they can only be obtained afterward.

From an operational perspective, the analysis of the acoustic data acquired by professional fishing vessels equipped with scientific echosounders (which represent the 420 majority of the industrial fishing fleet of the Peruvian anchovy fishery) would be of great interest in delivering a "real-time" monitoring of the juvenile anchovy areas. The recognition performances reported using single-frequency school features provide the basis for investigating this issue in future work. Cluster and school size and shape depend on meso- to submeso-scale physical features (e.g. upwelling plumes, eddies, oxygen 425 conditions) (Bertrand et al. 2006, 2008a). However, in the Humboldt Current system, the high variability of the physical forcing, which further shapes the aggregation patterns of anchovy (Bertrand et al., 2008a,b) might make the definition of robust patterns difficult. It could be expected to be more efficient for species recognition and adult/juvenile discrimination in ecosystems characterised by a more stable environment. Furthermore, the 
430 proposed model could also be used in a quantitative framework for the evaluation of juvenile and adult anchovy biomasses.

\section{Prospects}

We presented a novel approach for the school-based echogram-level characterization of fisheries acoustics data and demonstrated its relevance for an echogram

435 classification task. The proposed descriptors, computed as the density of different school categories, provided a compact yet meaningful representation of the distribution of fish schools within an echogram. Applied here to the discrimination of juvenile and adult anchovy school clusters, it could provide a synoptic representation of the temporal and/or spatial variations of the spatial distribution of fish at intermediate spatial scales (typically

440 from a few nautical miles to an entire survey zone).

It could not only reveal changes in species mixtures but also provide a descriptor of modifications of the spatial structuring of given fish species, for instance, induced by changes in the environmental conditions. Whereas the analysis of fish school characteristics would not allow to perceive smooth variations in the distribution of fish schools, the

445 proposed echogram-level features could detect both abrupt shifts in the observed types of fish schools as well as smoother relative changes in the densities of different school categories, which is typically expected to occur with school clusters involving species mixtures. We exploited here the BoF representation for classification purpose in this work, but it could be combined to any other type of multivariate statistical analysis in relation to 450 the considered application. As such, we believe that it provides a relevant basis for improving the exploitation of fisheries acoustics data in the context of the ecosystem approach to fisheries (Koslow 2009). 


\section{Acknowledgements}

This work is a contribution to the cooperation agreement between IMARPE and IRD and of the LMI DISCOH (joint International Laboratory "'Dynamics of the Humboldt Current system"). It was partially supported by grant IFIG from Europôle Mer. We thank the anonymous referees, Julian Burgos and the Editor for their valuable comments and suggestions to improve our manuscript. We also thank E. Ryall for his corrections and 460 suggestions to improve the clarity of the manuscript.

\section{References}

Anderson, C.I.H., Horne, J.K., and Boyle, J. 2007. Classifying multi-frequency fisheries acoustic data using a robust probabilistic classification technique. J. Ac. Soc. Am. 121(6): EL230-EL237.

Aoki, I. 1980. An analysis of the schooling behavior of fish: internal organisation and communication process. Bulletin of the Oceanic Research Institute of the University of Tokyo 12: 1-65.

Axelsen, B.E., Anker-Nilssen, T., Fossum, P., Kvamme, C., and Nøttestad, L. 2001. Pretty patterns but a simple strategy: predator-prey interactions between juvenile herring and Atlantic puffins observed with multibeam sonar. Can. J. Zool. 79(9): 1586-1596.

Ballón, M., Bertrand, A., Lebourges-Dhaussy, A., Gutierrez, M., Ayón, P., Grados, D., and Gerlotto, F. 2011. Is there enough zooplankton to feed forage fish populations off Peru? An acoustic (positive) answer. Prog. Oceanogr. 9(4): 360-381. 
Barange, M. 1994. Acoustic identification, classification and structure of biological patchiness on the edge of the Agulhas Bank and its relation to frontal features. S. Afr. J. Mar. Sc. 14: 333-347.

Bertrand, A., Ballon, M., and Chaigneau, A. 2010. Acoustic Observation of Living Organisms Reveals the Upper Limit of the Oxygen Minimum Zone. PLoS ONE 5(4): e10330.

Bertrand, A., Barbieri, M.A., Gerlotto, F., Leiva, F., and Córdova, J. 2006. Determinism and plasticity of fish schooling behaviour: the example of the South Pacific jack mackerel (Trachurus murphyi). Mar. Ecol. Prog. Ser. 311: 145-156.

Bertrand, A., Chaigneau, A., Peraltilla, S., Ledesma, J., Graco, M., Monetti, F. and Chavez, F.P. 2011. Oxygem: a fundamental regulating pelagic ecosystem structure in the coastal southeastern tropical Pacific. PLoS ONE 6(12): e29558.

Bertrand, A., Gerlotto, F., Bertrand, S., Gutierrez, M., Alza, L., Diaz, E., Espinoza, P., Ledesma, J., Quesquén, R., Peraltilla, S., and Chavez, F.P. 2008a. Schooling behavior and environmental forcing in relation to anchoveta distribution: an analysis across multiple spatial scales. Prog. Oceanogr. 79: 264-277.

Bertrand, A., Segura, M., Gutiérrez, M., and Vasquez, L. 2004. From small-scale habitat loopholes to decadal cycles: a habitat-based hypothesis explaining fluctuation in pelagic fish populations off Peru. Fish Fish. 5: 296-316.

Bertrand, S., Dewitte, B., Tam, J., Díaz, E., and Bertrand, A. 2008b. Spatial reorganisations in the coastal Humboldt Current system under oceanic climate forcing: 
portraying contrasted ecological scenarios from physics to fishers. Prog. Oceanogr. 79(2-4): 278-289.

Bishop, C.M. 2006. Pattern Recognition and Machine Learning. Springer, Berlin.

Breiman, L. 2001. Random Forests. Machine Learning 45(1): 5-32.

Burgos, J.M., and Horne, J.K. 2008. Acoustic characterization and classification of pelagic organism distributions.ICES J. Mar. Sci. 65: 1235-1247.

Chang, C.-C., and Lin, C.-J. 2011. LIBSVM : a library for support vector machines. ACM Transactions on Intelligent Systems and Technology 2(3): 1-27.

Chavez, F.P., Bertrand, A., Guevara-Carrasco, R., Soler, P., and Csirke, J. 2008. The northern humboldt current system: Brief history, present status and a view towards the future. Prog. Oceanogr. 79: 95-105.

Fablet, R., Lefort, R., Karoui, I., Berger, L., Massé, J., Scalabrin, C., and Boucher, J.-M. 2009. Classifying fish schools and estimating their species proportions in fisheryacoustic surveys. ICES J. Mar. Sci. 66(6): 1136-1142.

Fernandes, P.G. 2009. Classification trees for species identification of fish-school echotraces. ICES J. Mar. Sci. 66(6): 1073-1080.

Fréon, P., and Misund, O.A. 1999. Dynamics of Pelagic Fish Distribution and Behaviour: Effects on Fisheries and Stock Assessment. Blackwell Science, London. 
Gerlotto, F., Castillo, J., Saavedra, A., Barbieri, M.A., Espejo, M., and Cotel, P. 2004. Three-dimensional structure and avoidance behaviour of anchovy and common sardine schools in central southern Chile. ICES J. Mar. Sci. 61(7): 1120-1126.

Gutiérrez, M., Schwartzman, G., Bertrand, A., and Bertrand, S. 2007. Anchovy (Engraulis ringens) and sardine (Sardinops sagax) spatial dynamics and aggregation patterns in the Humboldt Current ecosystem, Peru, from 1983-2003. Fish. Oceanogr. 16(2): $155-168$.

520 Hammond, T.R., Swartzman, G.L., and Richardson, T.S. 2001. Bayesian estimation of fish school cluster composition applied to a Bering Sea acoustic survey. ICES J. Mar. Sci. 58(6): 1133-1149.

Haralambous, J., and Georgakarakos, S. 1996. Artificial neural networks as a tool for species identification of fish schools. ICES J. Mar. Sci. 53(2): 173-180.

525 Jech, J.M., and Michaels, W.L. 2006. A multifrequency method to classify and evaluate fisheries acoustics data. Canadian Journal of Fisheries and Aquatic Sciences 63(10): 2225-2235.

Kloser, R.J., Ryan, T.E., Young, J.W., and Lewis, M.E. 2009. Acoustic observations of micronekton fish on the scale of an ocean basin: potential and challenges. ICES J. Mar. Sci. 66(6): 998-1006.

Koslow, J.A. 2009. The role of acoustics in ecosystem-based fishery management. ICES J. Mar. Sci. 66(6): 966-973. 
Lebourges-Dhaussy, A., Coetzee, J., Hutchings, L., Roudaut, G., and Nieuwenhuys, C. 2009. Zooplankton spatial distribution along the South African coast studied by multifrequency acoustics, and its relationships with environmental parameters and anchovy distribution. ICES J. Mar. Sci. 66(6): 1055-1062.

Lefort, R., Fablet, R., and Boucher, J.M. 2011. Object recognition using proportion-based prior information: Application to fisheries acoustics. Pattern Recognition Letters 32(2): 153-158.

540 Nguyen, H.-G., Fablet, R., and Boucher, J.M. 2012. Keypoint-based analysis of sonar images: application to seabed recognition. IEEE Trans. on Geoscience and Remote Sensing, 50(4):1171-1184.

Petitgas, P., Reid, D., Carrera, P., Iglesias, M., Georgakarakos, S., Liorzou, B., and Masse, J. 2001. On the relation between schools, clusters of schools, and abundance in pelagic fish stocks. ICES J. Mar. Sci. 58(6): 1150-1160.

Salton, G., and McGill, M.J. 1983. Introduction to modern information retrieval. McGrawHill, New-York.

Scalabrin, C., Diner, N., Weill, A., Hillion, A., and Mouchot, M.C. 1996. Narrowband acoustic identification of monospecific fish shoals. ICES J. Mar. Sci. 53(2): 181-188.

550 Schölkopf, B., and Smola, A. 2002. Learning with kernels. MIT Press, Cambridge, MA.

Simmonds, E.J., Gutierrez, M., Chipollini, A., Gerlotto, F., Woillez, M., and Bertrand, A. 2009. Optimizing the design of acoustic surveys of Peruvian anchoveta. I ICES J. Mar. Sci. 66(6): 1341-1348. 
Simmonds, J., and MacLennan, D. 2005. Fisheries acoustics: theory and practice. Wiley555 Blackwell, Oxford, UK.

Sivic, J., and Zisserman, A. 2003. Video Google: A Text Retrieval Approach to Object Matching in Videos. Proc. IEEE Int. Conf. on Computer Vision, ICCV'2003, Nice, France, pp. 1470-1477.

Swartzman, G., Bertrand, A., Gutiérrez, M., Bertrand, S., and Vasquez, L. 2008. The 560 relationship of anchovy and sardine to water masses in the Peruvian Humboldt Current System from 1983 to 2005. Prog. Oceanogr. 79: 228-237.

Zuzunaga, J. 2002. Some shared fish stocks of the south eastern Pacific, Norway-FAO Expert Consultation on the Management of Shared Fish Stocks. Bergen (Norway), 710 Oct 2002. FAO report FAO-FIPP--R695, Roma, Italy. 


\section{List of Figures}

570 Figure 1. Example of a typical acoustic survey sampling off Peru, which consists of a series of coast-to-offshore transects from the north to the south of the Peruvian coast. Bifrequency acoustic echograms are acquired with a $38 \mathrm{kHz}$ and $120 \mathrm{kHz}$ hull mounted Simrad EK60 echosounder. Besides trawl catch, data are sampled within each transect.

Figure 2. Example of acoustic echograms associated with juvenile and adult anchovy

575 school clusters. Acoustic echograms associated with catch data predominantly depicting juvenile anchovy (more than $75 \%$ of anchovy smaller than $11 \mathrm{~cm}$ ) (panel a, left), acoustic echograms associated with catch data predominantly depicting juvenile anchovy (more than $75 \%$ of anchovy larger than $11 \mathrm{~cm}$ ) (panel $\mathrm{b}$, right). In both cases, both small and large school structures were observed. In all echograms the horizontal bar refers to 0.1 nautical 580 mile and the vertical one to 20 meters.

Figure 3. Sketch of the proposed echogram-level characterization. It involves two main steps: (i) the extraction of fish school categories from an unsupervised clustering within the considered fish school feature space for the dataset formed by all the schools detected in the

585 processed series of acoustic echograms (left); and (ii) the computation of the descriptor of a given echogram from a counting of the number of schools of the echogram falling in each school category (right). 
590 Figure 4. Mapping of the spatial distribution of areas of predominantly juvenile and adult anchovy off Peru during summer 2010 from catch data alone (a) and using the proposed approach based on a joint use of fisheries acoustics and catch data (b). As an effect of the catch sampling during the survey with a greater sampling effort on the juvenile anchovy population, the mapping issued from catch data alone might overestimate the area of the 595 region predominantly involving juvenile anchovy. By contrast, the joint use of catch and fisheries acoustics data seemed to deliver a finer analysis of the spatial distribution of the juvenile population. 


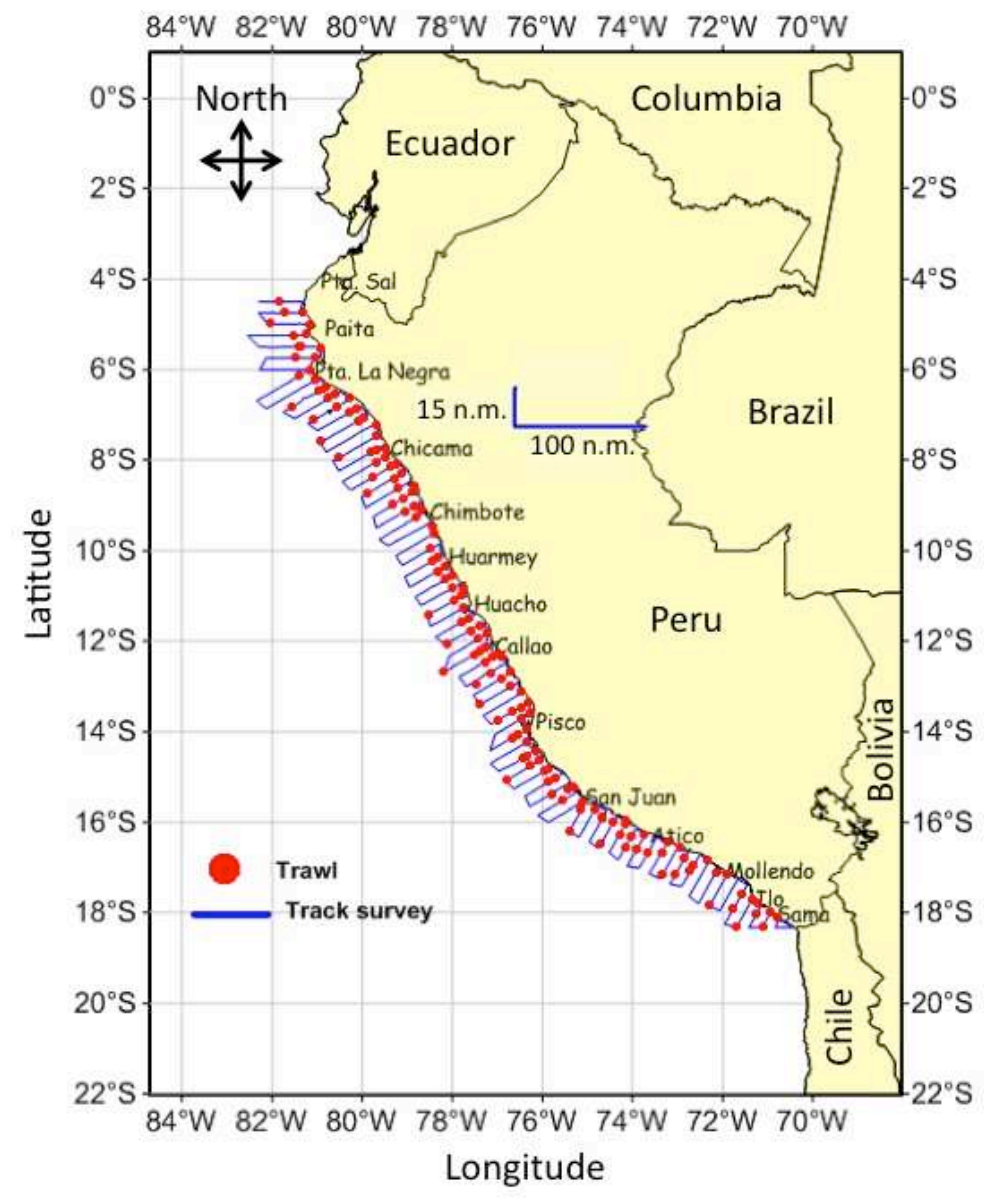

Figure 1. 

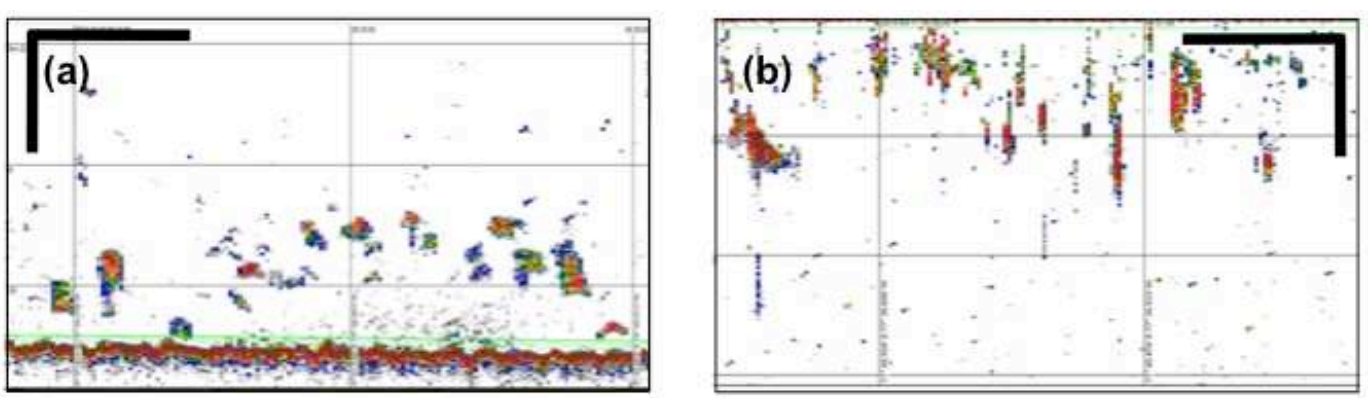

600
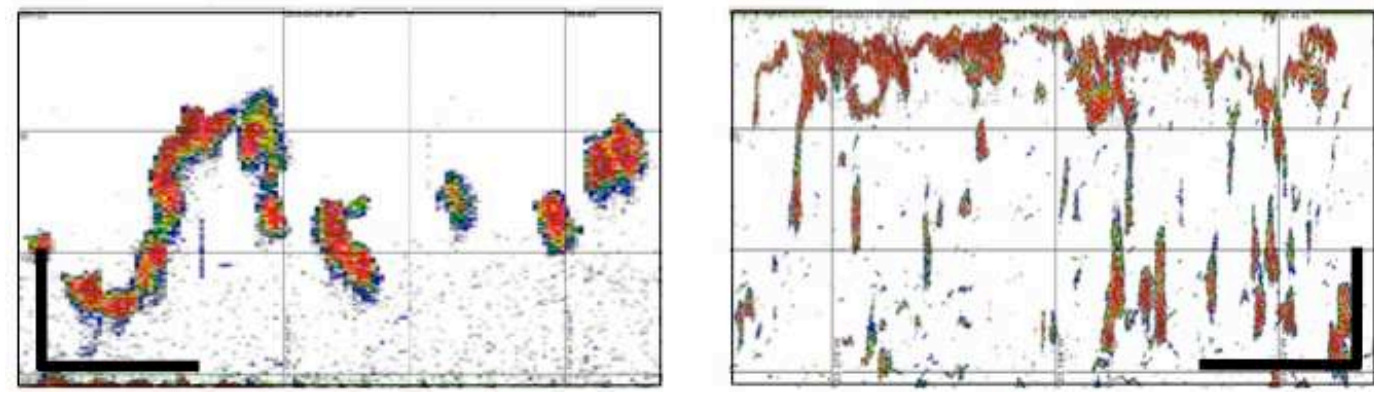

Figure 2. 


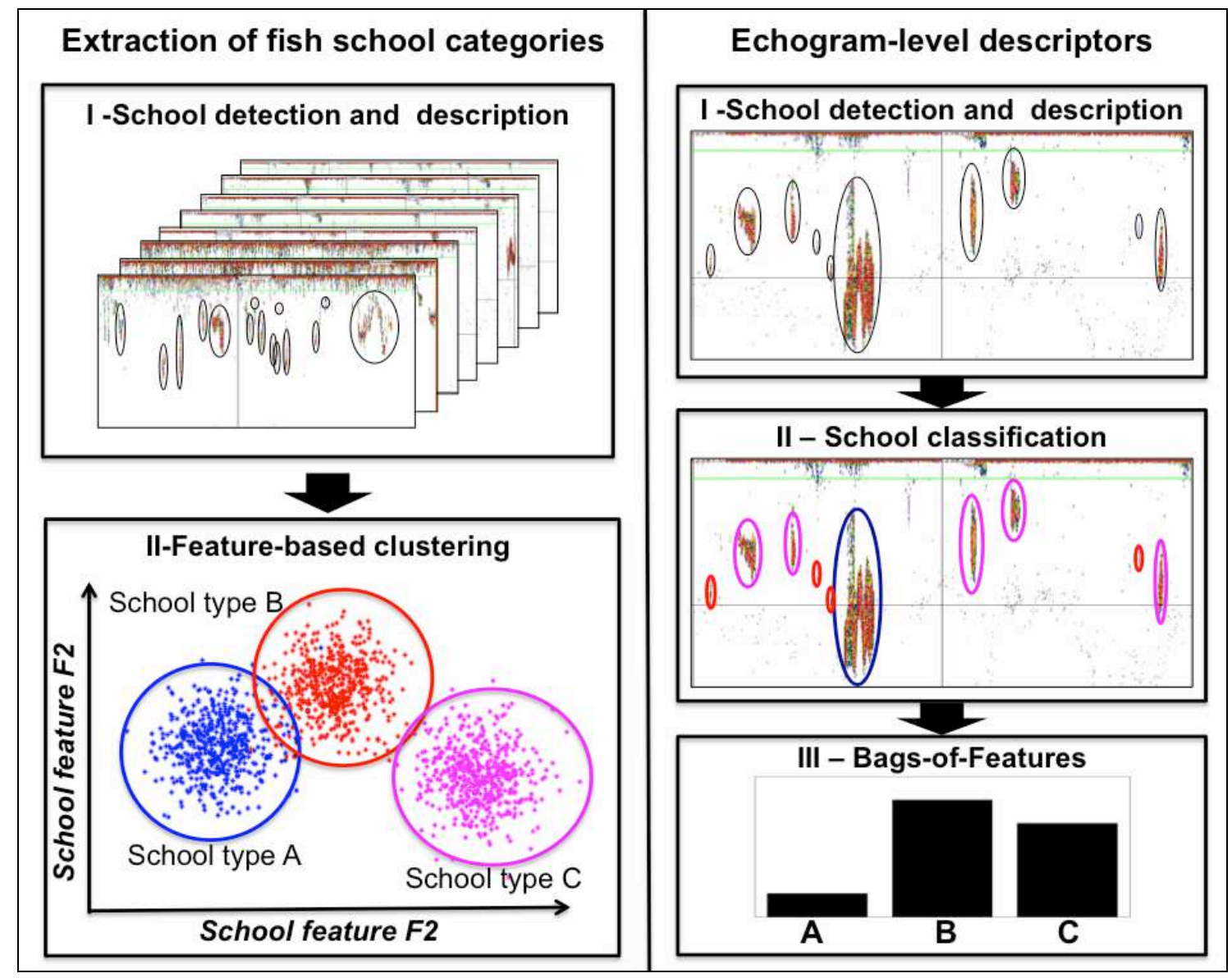

Figure 3. 

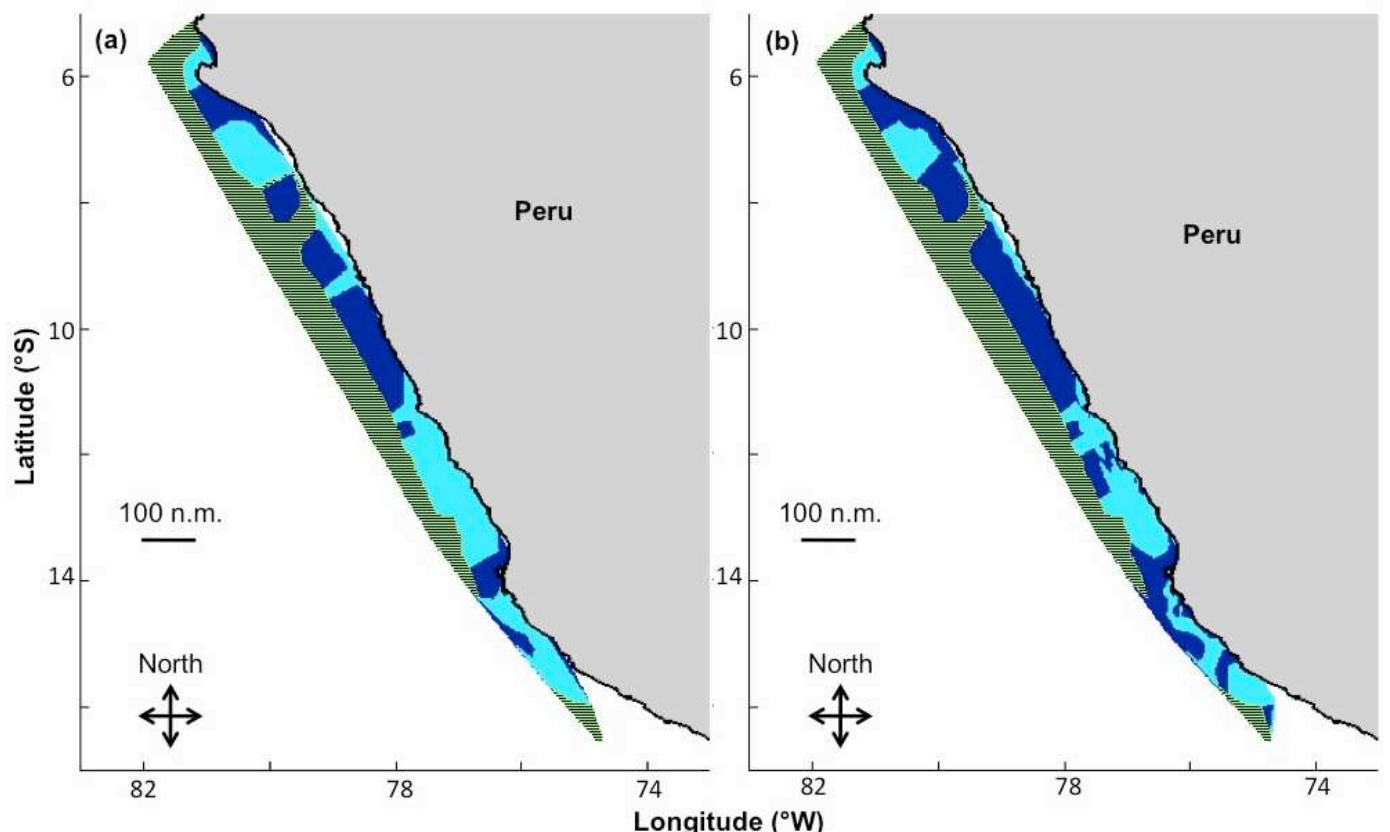

Figure 4. 


\section{List of Tables}

Table 1. Processed survey data

Table 2. Comparison of classification performances of different models. SVM-BoF and SVM-Marginals refer to echogram-level SVM classification models based on echogram feature vectors given respectively BoF (Bags-of-Features) and school marginals (see Material and Methods). SVM-school refers to a SVM classification model of individual

615 schools from the school feature vector. The best performance is emphasized in each case (bold).

Table 3. Classification performances using single-frequency or bi-frequency school characteristics. we compared mean correct classification rate using only single-frequency school features (resp., $38 \mathrm{kHz}$ and $120 \mathrm{kHz}$ school features) to the results reported in Table 6202 (third line). The best performance is emphasized in each case (bold).

Table 4. Classification performance of a model trained using a given survey dataset and applied to another survey dataset.

Table 5. Analysis of the intra-survey variability of school cluster characteristics between the predominantly juvenile anchovy clusters and the adult anchovy clusters, as a function of 625 school characteristics using rank-based correlation tests. We report the sign of the correlation $(\boldsymbol{\lambda}, \boldsymbol{y}$ or $\boldsymbol{\rightarrow})$ and the associated $\mathrm{p}$-value when significant $(*: \mathrm{p}<0.1, * *$ $\mathrm{p}<0.05, * * *: \mathrm{p}<0.001)$ with respect to six school features: depth $(D)$, area $(A), \mathrm{S}_{\mathrm{V}}$ value $\left(S_{V}\right)$, kurtosis $(K)$ and the difference in $\mathrm{S}_{\mathrm{V}}$ values at $38 \mathrm{kHz}$ and $120 \mathrm{kHz}$ signatures $\left(d S_{V}\right)$. 


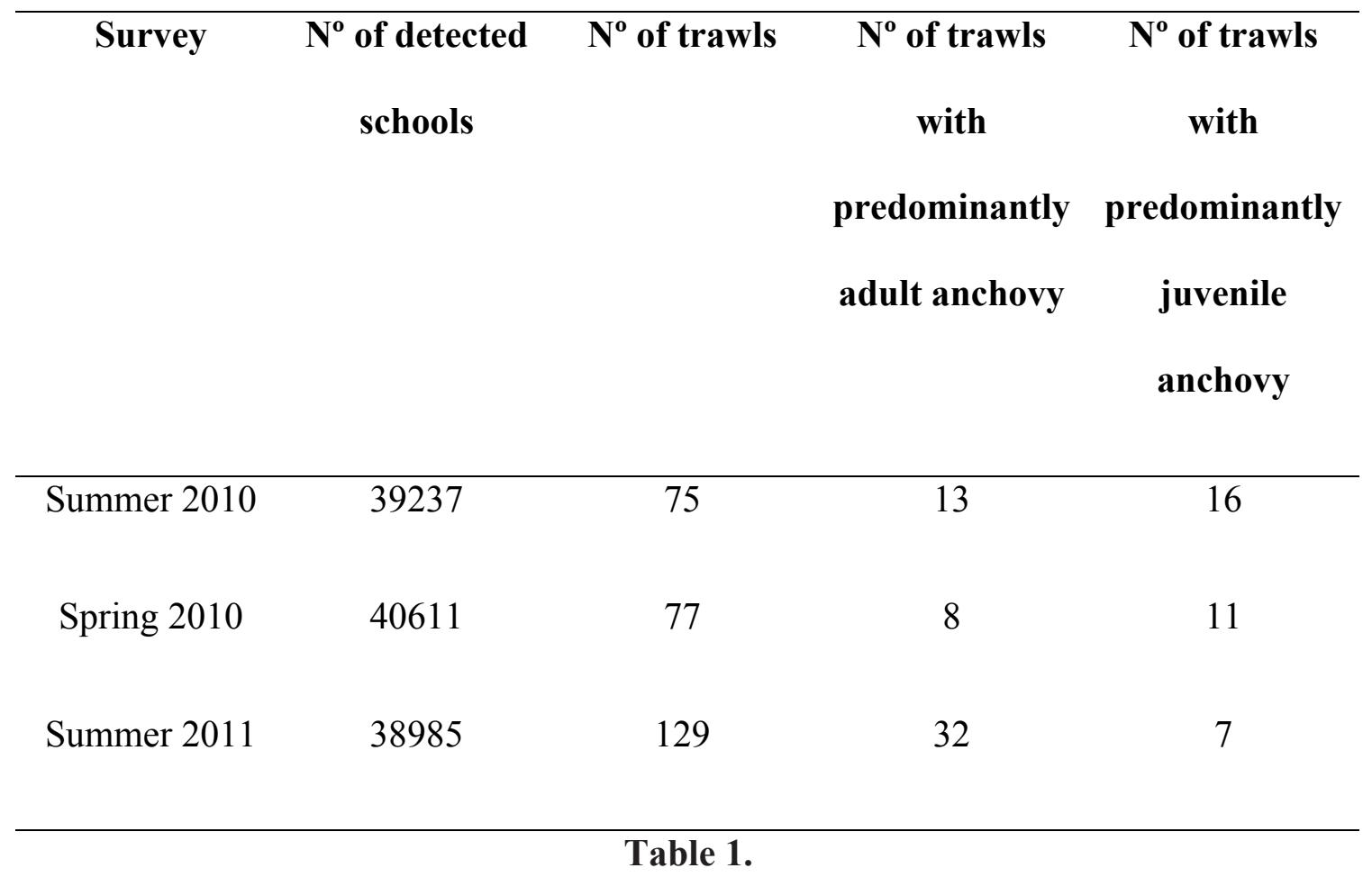

Table 1

\begin{tabular}{ccccc}
\hline Model & Summer 2010 & Spring 2010 & Summer 2011 & Mean \\
\hline SVM-BoF & $\mathbf{9 4 \%} \pm \mathbf{1 \%}$ & $\mathbf{9 1 \%} \pm \mathbf{3 \%}$ & $\mathbf{8 9 \%} \pm \mathbf{1 \%}$ & $\mathbf{9 1 \%}$ \\
SVM- & $79 \% \pm 2 \%$ & $80 \% \pm 2 \%$ & $79 \% \pm 1 \%$ & $79 \%$ \\
Marginals & & & & \\
SVM-School & $68 \% \pm 0.5 \%$ & $69 \% \pm 1 \%$ & $69 \% \pm 0.5 \%$ & $69 \%$ \\
& & & & \\
\hline
\end{tabular}

Table 2. 


\begin{tabular}{|c|c|c|c|c|}
\hline Bi-frequency & Summer 2010 & Spring 2010 & Summer 2011 & Mean \\
\hline \multicolumn{5}{|l|}{ vs. single- } \\
\hline \multicolumn{5}{|l|}{ frequency } \\
\hline \multicolumn{5}{|l|}{ school features } \\
\hline $38 \mathrm{kHz}$ & $94 \% \pm 1 \%$ & $83 \% \pm 3 \%$ & $89 \% \pm 2 \%$ & $89 \%$ \\
\hline $120 \mathrm{khZ}$ & $96 \% \pm 1 \%$ & $87 \% \pm 3 \%$ & $83 \% \pm 2 \%$ & $89 \%$ \\
\hline $38-120 \mathrm{kHz}$ & $94 \% \pm 1 \%$ & $91 \% \pm 3 \%$ & $89 \% \pm 1 \%$ & $91 \%$ \\
\hline
\end{tabular}

Table 3.

\begin{tabular}{ccc}
\hline Training dataset & Test dataset & $\begin{array}{c}\text { Mean correct } \\
\text { classification rate }\end{array}$ \\
& & \\
\hline Summer 2010 & Spring 2010 & $70 \% \pm 3 \%$ \\
Summer 2010 & Summer 2011 & $75 \% \pm 3 \%$ \\
Spring 2010 & Summer 2011 & $78 \% \pm 2 \%$ \\
\hline
\end{tabular}

Table 4.

640 


\begin{tabular}{ccccccc}
\hline Survey & $\boldsymbol{A}$ & $\boldsymbol{D}$ & $\boldsymbol{C}$ & $\boldsymbol{S}_{\boldsymbol{V}}$ & $\boldsymbol{K}$ & $\boldsymbol{d}$ \\
\hline Summer 2010 & $\boldsymbol{y}(* * *)$ & $\boldsymbol{\rightarrow}(-)$ & $\boldsymbol{y}(* * *)$ & $\boldsymbol{\lambda}(* * *)$ & $\boldsymbol{y}(* * *)$ & $\boldsymbol{\lambda}(* * *)$ \\
Spring 2010 & $\boldsymbol{y}(* * *)$ & $\boldsymbol{\lambda}(* * *)$ & $\boldsymbol{\rightarrow}(-)$ & $\boldsymbol{\lambda}(* * *)$ & $\boldsymbol{y}(* * *)$ & $\boldsymbol{\lambda}(-)$ \\
Summer 2011 & $\boldsymbol{y}(* * *)$ & $\boldsymbol{y}(* * *)$ & $\boldsymbol{y}(*)$ & $\boldsymbol{\lambda}(* * *)$ & $\boldsymbol{y}(* * *)$ & $\boldsymbol{\lambda}(-)$
\end{tabular}

Table 5. 